\title{
Optimum Plans of Step-Stress Life Tests Using Failure-Censored Data Form Burr Type-XII Distribution
}

\author{
Ali A. Ismail ${ }^{\mathrm{a}, 1}$ and K. Al-Habardi ${ }^{\mathrm{b}}$ \\ ${ }^{a}$ Cairo University, Faculty of Economics \& Political Science, Department of Statistics, Giza 12613, \\ Egypt \\ b King Saud University, College of Science, Department of Statistics and Operations Research, \\ Riyadh 11451, Saudi Arabia \\ ${ }^{1}$ ali.ismail@feps.edu.eg (Ali A. Ismail)
}

УДК 539.4

\section{Оптимальное планирование частично ускоренных ресурсных испытаний с цензурированием по времени для распределения Бурра ХII типа}

\begin{abstract}
Али А. Исмаил ${ }^{a}$ Х. Аль-Хабарди
a Каирский университет, Гиза, Египет

${ }^{\sigma}$ Университет им. Короля Сауда, Эр-Риад, Саудовская Аравия

Выполнено оптимальное планирование частично ускоренных ресурсных испытаний при пошаговом изменении напряжений с использованием иензурированных по времени данных из распределения Бурра XII типа. В рамках конщепџии максимальной вероятности выполнена оценка коэффициента ускорения испытаний и параметров распределения. В качестве критерия оптимизации планируемых частично ускоренных ресурсных испьтаний используется минимизация обобщенной асимптотической дисперсии для показателей максимальной вероятности параметров распределения. Эффективность предложенного метода демонстрируется на примере численных расчетов.
\end{abstract}

Ключевые слова: частично ускоренные ресурсные испытания, максимальная вероятность, распределение Бурра XII типа, оптимальное планирование испытаний, цензурирование II типа.

Introduction. Recently, the focus of inhabitant communities, manufacturing organizations and governments on the reliability issue is being increased. In fact, the majority of manufacturers increase their efforts to enhance the performance of their products in order to improve the trust and demand of their customers. However, information concerning the lifetime of materials of high reliability cannot be easily obtained when normal testing conditions are considered. Therefore, severe conditions (stresses) must be utilized in combination with normal (use) ones in order to obtain information about the lifetime of such materials in a shortest time. When such testing models are carried out under stresses, they are then known as partially accelerated life tests (PALT) or accelerated life tests (ALT). In the ALTs, it is supposed that the mathematical model used to explore the relation between the stress and the unit lifetime is either predefined or can be assumed. When that model is not applicable, the PALTs come to be a good alternative to the ALTs in order to investigate and examine specimens or materials of high reliability.

Nelson [1] indicated that the stresses can be categorized into common two types, namely; constant-stress and step-stress. The constant-stress test method runs all items only 
under either accelerated conditions or use ones until the experiment is ended, see for example, Ismail and Al Tamimi [2]. The second type is step-stress test method which in turn can be categorized into two types, namely; time-step-stress (TSS) and failure-step stress (FSS) tests. In the TSS test, all test units are run under use condition until a pre-specified time $\tau$. If a unit does not fail until that time, it is run under accelerated condition until it fails or the experiment is terminated. In the FSS test, the test units are run under use condition until a pre-assigned number of failures occurs and the unfailed units after that time are run under accelerated condition until the test is finished.

For an overview of the literature about the estimation and optimal design problems of step-stress PALTs, readers can be referred, for example, to Goel [3], Bai and Chung [4], Ismail [5-7], Ismail and Al-Habardi [8], among others.

The remaining of this article is organized as follows. Section 1 presents a lifetime model, namely, two-parameter Burr type-XII distribution. Section 2 presents the maximum likelihood estimations (MLEs) of the distribution parameters and acceleration factor. Also, the asymptotic confidence intervals of the model parameters are considered in this section. Section 3 considers the optimal design of step-stress PALTs. In Section 4 simulation studies are presented to illustrate the theoretical results. Section Six concludes the article.

1. The Model Description and Its Assumptions. This section describes the used model and presents its assumptions.

1.1. Burr Type-XII Distribution as a Lifetime Model. The Burr type-XII distribution, which was originally derived by Burr [9] received more attention by the researchers due to its broad applications in different fields, mainly in the modeling of failure time and reliability.

The two parameters Burr type-XII distribution has the following density function:

$$
f(t)=c k t^{(c-1)}\left(1+t^{c}\right)^{-(k+1)}, \quad t>0, c, k>0 .
$$

Its reliability function is given by

$$
R(t)=\left(1+t^{c}\right)^{-(k)}, \quad t>0 .
$$

The associated hazard function can be expressed by

$$
h(t)=\frac{c k t^{(c-1)}}{1+t^{c}} .
$$

This section presents the procedure of step-stress PALTs and its main assumptions.

\subsection{Test Procedure.}

(1) Putting the test units under normal (use) condition for a pre-specified stress change-time $\tau$.

(2) After that time $\tau$, each unit still alive is then tested under accelerated condition until it fails or the experimented is terminated.

\subsection{Test Assumptions.}

(1) The total lifetime $Y$ of an item can be expressed by

$$
Y=\left\{\begin{array}{lll}
T & \text { if } & T \leq \tau, \\
\tau+\beta^{-1}(T-\tau) & \text { if } & T>\tau,
\end{array}\right.
$$

where $T$ is the lifetime at use condition and $\beta$ is the acceleration factor. 
(2) The Burr type-XII distribution is assumed at both use and accelerated conditions.

(3) The failure times $y_{i}, i=1, \ldots, n$ are independent and identically distributed random variables (i.i.d.) random variables (r.v.).

2. Maximum Likelihood Estimation. The PDF of the total lifetime $Y$ for a specific item in step-stress PALTs is set as follows:

$$
f(y)=\left\{\begin{array}{lll}
0 & \text { if } \quad y \leq 0 \\
f_{1}(y) & \text { if } \quad 0<y \leq \tau \\
f_{2}(y) & \text { if } \quad y>\tau
\end{array}\right.
$$

where $f_{1}(y)=c k y^{(c-1)}\left(1+y^{c}\right)^{-(k+1)}, c, k>0$ which is given in Eq. (1), and $f_{2}(y)=$ $=\beta c k[\tau+\beta(y-\tau)]^{(c-1)}\left[1+\{\tau+\beta(y-\tau)\}^{c}\right]^{-(k+1)}, c, k>0, \beta>1$ is derived by the transformation variable technique using the equations given in (1) and (4).

When the pre-specified number of failures $(r)$ is reached, the test ends immediately.

The observed lifetimes are expressed as $y_{(1)} \leq \ldots \leq y_{\left(n_{u}\right)} \leq \tau \leq y_{\left(n_{u}+1\right)} \leq \ldots \leq y_{(r)}$, where $r=n_{u}+n_{a}$ is the total number of failures. Two indictor functions can be then considered, namely, $\delta_{1 i}, \delta_{2 i}$, as

$$
\delta_{1 i}=\left\{\begin{array}{ll}
1 & y_{(i)} \leq \tau \\
0 & \text { otherwise }
\end{array} \quad i=1,2, \ldots, n\right.
$$

and

$$
\delta_{2 i}=\left\{\begin{array}{ll}
1 & y_{(i)}<\tau \leq y_{(r)} \\
0 & \text { otherwise }
\end{array} \quad i=1,2, \ldots, n .\right.
$$

The likelihood function of the lifetimes $y_{1}, \ldots, y_{n}$ of $n$ items under step-stress PALTs can be written as

$$
\begin{gathered}
L(y ; \beta, c, k)=\prod_{i=1}^{n}\left\{f_{1}\left(y_{i}\right)\right\}^{\delta_{1 i}}\left\{f_{2}\left(y_{i}\right)\right\}^{\delta_{2 i}}\left\{R\left(y_{(r)}\right)\right\}^{\bar{\delta}_{1 i} \bar{\delta}_{2 i}}= \\
\left.=\prod_{i=1}^{n}\left\{c k y^{c-1}\left(1+y_{i}^{c}\right)^{-(k+1)}\right)\right\}^{\delta_{1 i} \times} \\
\times\left\{\beta c k\left[\tau+\beta\left(y_{i}-\tau\right)\right]^{c-1}\left[1+\left(\tau+\beta\left(y_{i}-\tau\right)\right)^{c}\right]^{-(k+1)}\right\}^{\delta_{2 i}}\left\{1+\left[\tau+\beta\left(y_{(r)}-\tau\right)\right]^{c}\right\}^{-k \delta_{1 i} \bar{\delta}_{2 i}},
\end{gathered}
$$

where $\bar{\delta}_{1 i}=1-\delta_{1 i}$ and $\bar{\delta}_{2 i}=1-\delta_{2 i}$.

Practically, the maximization of the natural logarithm of the likelihood function is much simpler than that of the likelihood function itself. The natural logarithm of the likelihood function can be defined as

$$
\begin{gathered}
\ln L=n_{0} \ln c+n_{0} \ln k+(c-1)\left\{\sum_{i=1}^{n} \delta_{1 i} \ln y_{i}+\sum_{i=1}^{n} \delta_{2 i} \ln A\right\}+ \\
+n_{a} \ln \beta-(k+1)\left\{\sum_{i=1}^{n} \delta_{1 i} \ln \left(1+y_{i}^{c}\right)+\sum_{i=1}^{n} \delta_{2 i} \ln \left(1+A^{c}\right)\right\}-k\left(n-n_{0}\right) \ln \left(1+D^{c}\right),
\end{gathered}
$$


where

$$
\begin{gathered}
A=\tau+\beta\left(y_{i}-\tau\right), \quad D=\tau+\beta\left(y_{(r)}-\tau\right), \quad \sum_{i=1}^{n} \delta_{1 i}=n_{u}, \\
\sum_{i=1}^{n} \delta_{2 i}=n_{a}, \quad \sum_{i=1}^{n} \bar{\delta}_{1 i} \bar{\delta}_{2 i}=n-n_{u}-n_{a}, \quad n_{0}=n_{u}+n_{a} .
\end{gathered}
$$

The first partial derivatives of $\ln L$ with respect to (w.r.t.) $\beta, c$, and $k$ are given by

$$
\begin{aligned}
& \frac{\partial \ln L}{\partial \beta}=\frac{n_{a}}{\beta}-(c-1) \sum_{i=1}^{n} \delta_{2 i}\left(y_{i}-\tau\right) A^{-1}-k c\left(n-n_{0}\right) D^{c-1}\left(y_{(r)}-\tau\right)\left(1+D^{c}\right)^{-1}- \\
& -(k+1) c \sum_{i=1}^{n} \delta_{2 i} A^{c-1}\left(y_{i}-\tau\right)\left(1+A^{c}\right)^{-1} \\
& \frac{\partial \ln L}{\partial c}=\frac{n_{0}}{c}+\sum_{i=1}^{n} \delta_{1 i} \ln y_{i}+\sum_{i=1}^{n} \delta_{2 i} \ln A-k\left(n-n_{0}\right) D^{c} \ln D\left(1+D^{c}\right)^{-1}- \\
& -(k+1)\left\{\sum_{i=1}^{n} \delta_{1 i} y_{i}^{c} \ln y_{i}\left(1+y_{i}^{c}\right)^{-1}+\sum_{i=1}^{n} \delta_{2 i} A^{c} \ln A\left(1+A^{c}\right)^{-1}\right\}
\end{aligned}
$$

and

$$
\frac{\partial \ln L}{\partial k}=\frac{n_{0}}{k}-\sum_{i=1}^{n} \delta_{1 i} \ln \left(1+y_{i}^{c}\right)-\sum_{i=1}^{n} \delta_{2 i} \ln \left(1+A^{c}\right)-\left(n-n_{0}\right) \ln \left(1+D^{c}\right) .
$$

Set $\frac{\partial \ln L}{\partial k}=0$ we get

$$
\frac{n_{0}}{k}=\sum_{i=1}^{n} \delta_{1 i} \ln \left(1+y_{i}^{c}\right)+\sum_{i=1}^{n} \delta_{2 i} \ln \left(1+A^{c}\right)+\left(n-n_{0}\right) \ln \left(1+D^{c}\right) .
$$

The MLE of $k$ is then given by

$$
\hat{k}=\frac{n_{0}}{a_{1}}
$$

where

$$
a_{1}=\sum_{i=1}^{n} \delta_{1 i} \ln \left(1+y_{i}^{c}\right)+\sum_{i=1}^{n} \delta_{2 i} \ln \left(1+A^{c}\right)+\left(n-n_{0}\right) \ln \left(1+D^{c}\right) .
$$

Substitute $\hat{k}$ into Eqs. (5) and (6), then we have the following two nonlinear equations:

$$
\frac{n_{a}}{\hat{\beta}}+(\hat{c}-1) \sum_{i=1}^{n} \delta_{2 i}\left(y_{i}-\tau\right) A^{-1}-\left(\frac{n_{0}}{a_{1}}+1\right) a_{4}-\frac{n_{0}}{a_{1}} a_{5}=0 \ldots
$$

and

$$
\frac{n_{0}}{\hat{c}}+\sum_{i=1}^{n} \delta_{1 i} \ln y_{i}+\sum_{i=1}^{n} \delta_{2 i} \ln A-\left(\frac{n_{0}}{a_{1}}+1\right) a_{2}-\frac{n_{0}}{a_{1}} a_{3}=0, \ldots
$$


where

$$
\begin{gathered}
a_{2}=\sum_{i=1}^{n} \delta_{1 i} y_{i}^{\hat{c}} \ln y_{i}\left(1+y_{i}^{\hat{c}}\right)^{-1}+\sum_{i=1}^{n} \delta_{2 i} A^{\hat{c}} \ln A\left(1+A^{\hat{c}}\right)^{-1}, \\
a_{3}=\left(n-n_{0}\right) D^{\hat{c}} \ln D\left(1+D^{\hat{c}}\right)^{-1}, \quad a_{4}=\hat{c} \sum_{i=1}^{n} \delta_{2 i} A^{\hat{c}-1}\left(y_{i}-\tau\right)\left(1+A^{\hat{c}}\right)^{-1}, \\
a_{5}=\left(n-n_{0}\right) \hat{c} D^{\hat{c}-1}\left(y_{(r)}-\tau\right)\left(1+D^{\hat{c}}\right)^{-1} .
\end{gathered}
$$

It is shown that the MLEs of the model parameters cannot be obtained in a closed form. Hence, some iterative methods such as Newton-Raphson method are necessary.

Regarding the asymptotic Fisher information matrix, the elements can be found as the negative of the second partial derivatives of the natural logarithm of the likelihood function w.r.t. the parameters of the model as indicated below.

$$
F=\left[\begin{array}{ccc}
-\frac{\partial^{2} \ln L}{\partial^{2} \beta^{2}} & -\frac{\partial^{2} \ln L}{\partial \beta \partial c} & -\frac{\partial^{2} \ln L}{\partial \beta \partial k} \\
-\frac{\partial^{2} \ln L}{\partial c \partial \beta} & -\frac{\partial^{2} \ln L}{\partial^{2} c^{2}} & -\frac{\partial^{2} \ln L}{\partial c \partial k} \\
-\frac{\partial^{2} \ln L}{\partial k \partial \beta} & -\frac{\partial^{2} \ln L}{\partial k \partial c} & -\frac{\partial^{2} \ln L}{\partial^{2} k^{2}}
\end{array}\right]
$$

The elements of the above matrix are defined and expressed in more details in Appendix A.

The approximate $100(1-\gamma) \%$ confidence intervals for the model parameters $\beta, c$, and $k$ can be, respectively, presented by

$$
\hat{\beta} \pm Z_{\gamma / 2} \sqrt{F_{11}^{-1}}, \quad \hat{c} \pm Z_{\gamma / 2} \sqrt{F_{22}^{-1}}, \quad \hat{k} \pm Z_{\gamma / 2} \sqrt{F_{33}^{-1}},
$$

where $Z_{\gamma / 2}$ is the upper $(\gamma / 2)$ percentile of the standard normal distribution.

3. Optimum Test Plan. This section presents the optimal plans of step-stress PALTs. The optimal plans provide the most accurate estimates of life at use condition. Based on a certain optimality criterion, we can choose the best or optimal stress-change time. The D-optimality criterion is adopted in this paper. It is a more general optimality criterion. It takes into account the overall parameter space. It minimizes the generalized asymptotic variance (GAV) of MLEs of the model parameters.

The GAV of the MLEs of the model parameters is defined as the reciprocal of the determinant of the Fisher information matrix $(F)$, see Bai et al. [10]. That is

$$
\operatorname{GAV}(\hat{\beta}, \hat{c}, \hat{k})=\frac{1}{|F|} \text {. }
$$

Now, the optimum test plan for products having Burr-XII distribution is to find the optimum stress-change time $\tau$ such that the GAV of the MLE of the model parameters at use condition is minimized. The minimization of the GAV over $\tau$ can be achieved by solving the following equation:

$$
\frac{\partial G A V}{\partial \tau}=0
$$


It can be then reduced to the equation below:

$$
\frac{\partial|F|}{\partial \tau}=0
$$

where $|F|$ and its derivative w.r.t. $\tau$ are defined in Appendix B.

The above equation can be solved by using an iterative method such as NewtonRaphson to obtain the optimal value of $\tau$. Accordingly, the expected optimal number of failed items under use and accelerated conditions are expressed, respectively, as

$$
\begin{gathered}
n P_{u}=n\left(1-\left(1+\left(\tau^{*}\right)^{\hat{c}}\right)^{-(\hat{k})},\right. \\
n P_{a}=n\left(1+\left(\tau^{*}\right)^{\hat{c}}\right)^{-(\hat{k})}\left(1-\left(1+\left(\hat{\beta}\left(y_{(r)}-\tau^{*}\right)\right)^{\hat{c}}\right)^{-(\hat{k})}\right),
\end{gathered}
$$

where $P_{u}$ is the probability that a tested item under use condition fails by $y_{(r)}$ and $P_{a}$ is the probability that a tested item under accelerated condition fails by $y_{(r)}$.

4. Simulation Studies. Monte Carlo simulation studies are conducted to discuss the performance of the MLEs in terms of their mean square errors (MSE) for different choices of $n, c, \beta$, and $k$ values based on failure censored data in step-stress PALTs. Also, the variance of the MLEs is computed and $95 \%$ approximate confidence intervals (ACI) of the model parameters are constructed. In addition, the optimal design results of the life test are discussed.

Average values of the MLEs with MSEs and 95\% ACIs are obtained based on samples generated from Burr type-XII distribution of various combinations of true parameter values of $c, \beta$, and $k$. The used combinations are $(0.5,2,1),(1.5,2,0.5),(1,2,0.5)$ and $(0.4,2$, 0.5 ) with sample sizes set at $20,25,30,40,50,75$, and 100 . The number of replications used for each sample size is 20,000 .

Tables 1-4 show a summary of the estimation results when $\tau=3$ and $r=0.75 n$. The estimates, MSEs, variance, lower and upper limits for $c, \beta$, and $k$ are presented for different sample sizes with different combinations of the parameter values. As indicated from the results that the MSEs of the estimates become smaller as the sample size increases. Also, the confidence intervals become narrower as the sample size increases. That is, we obtain good estimates.

$\mathrm{T}$ a b 1 e 1

Average Values of the Estimates, MSEs, Variances, and Confidence Limits for $(c, \beta, k, \tau, r)=(0.5,2,1,3,0.75 n)$

\begin{tabular}{|c|c|c|c|c|c|c||}
\hline$n$ & Parameters & Estimates & MSEs & Variance & $\begin{array}{c}\text { Lower } \\
\text { bound }\end{array}$ & $\begin{array}{c}\text { Upper } \\
\text { bound }\end{array}$ \\
\hline 1 & 2 & 3 & 4 & 5 & 6 & 7 \\
\hline 20 & $c$ & 0.5558331 & 0.02000864 & 0.0169 & 0.1673 & 0.6768 \\
& $\beta$ & 1.4039627 & 0.79268474 & 0.4374 & 0.7038 & 3.2965 \\
& $k$ & 1.0638589 & 0.07783380 & 0.0738 & 0.3924 & 1.4570 \\
\hline 25 & $c$ & 0.5510322 & 0.01529511 & 0.0127 & 0.3092 & 0.7508 \\
& $\beta$ & 1.4554021 & 0.68603244 & 0.3895 & 0.7787 & 3.2251 \\
& $k$ & 1.0533883 & 0.06258916 & 0.0597 & 0.5507 & 1.5089 \\
\hline 30 & $c$ & 0.5488667 & 0.01308809 & 0.0107 & 0.4173 & 0.8228 \\
& $\beta$ & 1.4934548 & 0.60259759 & 0.3460 & 0.8471 & 3.1530 \\
& $k$ & 1.0471862 & 0.05159331 & 0.0494 & 0.8183 & 1.6893 \\
\hline
\end{tabular}


Optimum Plans of Step-Stress Life Tests ...

\begin{tabular}{|c|c|c|c|c|c|c||}
\hline \multicolumn{1}{|c|}{} & \multicolumn{3}{c|}{ Continued Table 1 } \\
\hline \hline \multirow{2}{*}{40} & 2 & 3 & 4 & 5 & 6 & 7 \\
& $c$ & 0.5443688 & 0.01093166 & 0.0090 & 0.4185 & 0.7898 \\
& $\beta$ & 1.5471787 & 0.50230063 & 0.2973 & 0.7464 & 2.8837 \\
& $k$ & 1.0387819 & 0.03989735 & 0.0384 & 0.3957 & 1.1638 \\
\hline \multirow{2}{*}{50} & $c$ & 0.5255432 & 0.007638101 & 0.0070 & 0.3532 & 0.6809 \\
& $\beta$ & 1.5833846 & 0.431768628 & 0.2582 & 0.7769 & 2.7688 \\
& $k$ & 1.0352212 & 0.030679060 & 0.0294 & 0.5132 & 1.1858 \\
\hline \multirow{2}{*}{75} & $c$ & 0.5130436 & 0.00311434 & 0.0030 & 0.3805 & 0.5973 \\
& $\beta$ & 1.6434398 & 0.32589565 & 0.1988 & 1.1263 & 2.8740 \\
& $k$ & 1.0204070 & 0.01569335 & 0.0153 & 0.7370 & 1.2215 \\
\hline \multirow{2}{*}{100} & $c$ & 0.5143938 & 0.002584185 & 0.0024 & 0.4208 & 0.6119 \\
& $\beta$ & 1.6831689 & 0.263691937 & 0.1633 & 1.2079 & 2.7920 \\
& $k$ & 1.0189076 & 0.012451442 & 0.0121 & 0.9435 & 1.3746 \\
\hline
\end{tabular}

$\mathrm{T}$ a b 1 e 2

Average Values of the Estimates, MSEs, Variances, and Confidence Limits for $(c, \beta, k, \tau, r)=(1.5,2,0.5,3,0.75 n)$

\begin{tabular}{|c|c|c|c|c|c|c|}
\hline$n$ & Parameters & Estimates & MSEs & Variance & $\begin{array}{l}\text { Lower } \\
\text { bound }\end{array}$ & $\begin{array}{l}\text { Upper } \\
\text { bound }\end{array}$ \\
\hline \multirow[t]{3}{*}{20} & c & 1.7570995 & 1.02382632 & 0.9578 & 0.1057 & 3.9421 \\
\hline & $\beta$ & 1.6075434 & 0.54472141 & 0.3907 & 0.8744 & 3.3247 \\
\hline & $k$ & 0.5183056 & 0.03163381 & 0.0313 & 0.0761 & 0.7697 \\
\hline \multirow[t]{3}{*}{25} & $c$ & 1.6987884 & 0.47179510 & 0.4323 & 0.7509 & 3.3282 \\
\hline & $\beta$ & 1.6235957 & 0.47828527 & 0.3366 & 0.6884 & 2.9627 \\
\hline & $k$ & 0.5118737 & 0.02101283 & 0.0209 & 0.2081 & 0.7744 \\
\hline \multirow[t]{3}{*}{30} & $c$ & 1.6563729 & 0.19159083 & 0.1671 & 1.1031 & 2.7057 \\
\hline & $\beta$ & 1.6501155 & 0.41601437 & 0.2936 & 1.0774 & 3.2015 \\
\hline & $k$ & 0.5126854 & 0.01617681 & 0.0160 & 0.1669 & 0.6630 \\
\hline \multirow[t]{3}{*}{40} & c & 1.6093054 & 0.11626641 & 0.1043 & 1.0507 & 2.3169 \\
\hline & $\beta$ & 1.6839737 & 0.33755963 & 0.2377 & 0.6734 & 2.5845 \\
\hline & $k$ & 0.5188141 & 0.01339067 & 0.0130 & 0.1798 & 0.6274 \\
\hline \multirow[t]{3}{*}{50} & $c$ & 1.5847601 & 0.08622207 & 0.0790 & 1.4492 & 2.5513 \\
\hline & $\beta$ & 1.7033682 & 0.29343447 & 0.2055 & 0.7305 & 2.5073 \\
\hline & $k$ & 0.5228587 & 0.01213649 & 0.0116 & 0.2419 & 0.6644 \\
\hline \multirow[t]{3}{*}{75} & $c$ & 1.5613185 & 0.051841188 & 0.0481 & 1.3211 & 2.1816 \\
\hline & $\beta$ & 1.7432533 & 0.217272645 & 0.1514 & 0.7280 & 2.2531 \\
\hline & $k$ & 0.5023715 & 0.007077984 & 0.0071 & 0.4288 & 0.7584 \\
\hline \multirow[t]{3}{*}{100} & $c$ & 1.553086 & 0.038601260 & 0.0358 & 0.8031 & 1.5446 \\
\hline & $\beta$ & 1.771735 & 0.174691394 & 0.1226 & 1.1030 & 2.4755 \\
\hline & $k$ & 0.501235 & 0.004560504 & 0.0046 & 0.4978 & 0.7625 \\
\hline
\end{tabular}


Ali A. Ismail and K. Al-Habardi

$\mathrm{T}$ a b 1 e 3

Average Values of the Estimates, MSEs, Variances, and Confidence Limits

for $(c, \beta, k, \tau, r)=(1,2,0.5,3,0.75 n)$

\begin{tabular}{|c|c|c|c|c|c|c|}
\hline$n$ & Parameters & Estimates & MSEs & Variance & $\begin{array}{l}\text { Lower } \\
\text { bound }\end{array}$ & $\begin{array}{l}\text { Upper } \\
\text { bound }\end{array}$ \\
\hline \multirow[t]{3}{*}{20} & $c$ & 1.143961 & 0.19859550 & 0.1829 & 0.8465 & 2.2847 \\
\hline & $\beta$ & 1.473192 & 0.65951500 & 0.3858 & 0.0975 & 2.5789 \\
\hline & $k$ & 0.547272 & 0.02754216 & 0.0255 & 0.1604 & 0.7871 \\
\hline \multirow[t]{3}{*}{25} & $c$ & 1.132550 & 0.18771716 & 0.1702 & 0.4688 & 2.0858 \\
\hline & $\beta$ & 1.542232 & 0.55121442 & 0.3417 & 0.0643 & 2.3557 \\
\hline & $k$ & 0.517588 & 0.02098195 & 0.0207 & 0.0942 & 0.6578 \\
\hline \multirow[t]{3}{*}{30} & $c$ & 1.1065001 & 0.11910894 & 0.1078 & 0.2643 & 1.5512 \\
\hline & $\beta$ & 1.5766455 & 0.48121523 & 0.3020 & 1.0132 & 3.1675 \\
\hline & $k$ & 0.5202578 & 0.01753665 & 0.0171 & 0.1536 & 0.6666 \\
\hline \multirow[t]{3}{*}{40} & $c$ & 1.0854660 & 0.06071411 & 0.0534 & 0.6080 & 1.5131 \\
\hline & $\beta$ & 1.6165245 & 0.39292298 & 0.2459 & 1.0526 & 2.9964 \\
\hline & $k$ & 0.5209746 & 0.01438465 & 0.0139 & 0.3931 & 0.8567 \\
\hline \multirow[t]{3}{*}{50} & $c$ & 1.0690090 & 0.04405074 & 0.0393 & 0.7131 & 1.4901 \\
\hline & $\beta$ & 1.6501520 & 0.3303979 & 0.2107 & 0.9175 & 2.7167 \\
\hline & $k$ & 0.5230048 & 0.01316781 & 0.0126 & 0.2061 & 0.6468 \\
\hline \multirow[t]{3}{*}{75} & $c$ & 1.0414909 & 0.02231290 & 0.0206 & 0.7892 & 1.3517 \\
\hline & $\beta$ & 1.7027006 & 0.24449222 & 0.1561 & 1.2837 & 2.8325 \\
\hline & $k$ & 0.5022402 & 0.00602722 & 0.0060 & 0.2177 & 0.5219 \\
\hline \multirow[t]{3}{*}{100} & $c$ & 1.0323358 & 0.015548694 & 0.0145 & 0.8172 & 1.2893 \\
\hline & $\beta$ & 1.7315798 & 0.202133419 & 0.1301 & 1.2973 & 2.7112 \\
\hline & $k$ & 0.5053709 & 0.004267453 & 0.0042 & 0.3273 & 0.5825 \\
\hline
\end{tabular}

$\mathrm{T}$ a b 1 e 4

Average Values of the Estimates, MSEs, Variances, and Confidence Limits

for $(c, \beta, k, \tau, r)=(0.4,2,0.5,3,0.75 n)$

\begin{tabular}{|c|c|c|c|c|c|c|}
\hline$n$ & Parameters & Estimates & MSEs & Variance & $\begin{array}{c}\text { Lower } \\
\text { bound }\end{array}$ & $\begin{array}{c}\text { Upper } \\
\text { bound }\end{array}$ \\
\hline 1 & 2 & 3 & 4 & 5 & 6 & 7 \\
\hline 20 & $c$ & 0.4984639 & 0.25801551 & 0.2483 & 0.1562 & 0.9751 \\
& $\beta$ & 1.3282733 & 0.94312057 & 0.4919 & 0.6108 & 3.9751 \\
& $k$ & 0.5223291 & 0.03438470 & 0.0309 & 0.0210 & 0.6521 \\
\hline 25 & $c$ & 0.4688156 & 0.07526569 & 0.0705 & 0.0548 & 0.5304 \\
& $\beta$ & 1.3756230 & 0.83089715 & 0.4411 & 0.8209 & 3.1791 \\
& $k$ & 0.5187950 & 0.02588938 & 0.0255 & 0.5274 & 1.1364 \\
\hline 30 & $c$ & 0.4403062 & 0.02141981 & 0.0198 & 0.1047 & 0.5926 \\
& $\beta$ & 1.4244297 & 0.72943502 & 0.3982 & 0.2477 & 2.6291 \\
& $k$ & 0.5130699 & 0.01897816 & 0.0178 & 0.4190 & 0.9841 \\
\hline
\end{tabular}


Optimum Plans of Step-Stress Life Tests ...

\begin{tabular}{|c|c|c|c|c|c|c||}
\hline \multicolumn{9}{|c|}{} & \multicolumn{3}{c}{ Continued Table 4 } \\
\hline \multirow{2}{*}{1} & 2 & 3 & 4 & 5 & 6 & 7 \\
\hline \multirow{2}{*}{40} & $c$ & 0.4259220 & 0.008332961 & 0.0077 & 0.2067 & 0.5810 \\
& $\beta$ & 1.4821521 & 0.612243463 & 0.3441 & 0.6356 & 2.9481 \\
& $k$ & 0.5098138 & 0.011472813 & 0.0114 & 0.2354 & 0.6897 \\
\hline \multirow{2}{*}{50} & $c$ & 0.4242359 & 0.006346346 & 0.0058 & 0.1401 & 0.4407 \\
& $\beta$ & 1.5267159 & 0.527254038 & 0.3033 & 0.6688 & 2.8088 \\
& $k$ & 0.5082884 & 0.009183374 & 0.0091 & 0.4831 & 0.8933 \\
\hline \multirow{2}{*}{75} & $c$ & 0.4220691 & 0.004551284 & 0.0041 & 0.3563 & 0.6062 \\
& $\beta$ & 1.6037429 & 0.386799434 & 0.2298 & 1.0614 & 2.9405 \\
& $k$ & 0.5083173 & 0.007267912 & 0.0072 & 0.2343 & 0.5669 \\
\hline \multirow{2}{*}{100} & $c$ & 0.4173501 & 0.004153889 & 0.0039 & 0.3669 & 0.6102 \\
& $\beta$ & 1.6418385 & 0.323044804 & 0.1948 & 1.3501 & 2.8650 \\
& $k$ & 0.5051016 & 0.006595488 & 0.0066 & 0.2836 & 0.6013 \\
\hline
\end{tabular}

T a b 1 e 5

The Results of Optimal Design of Step-Stress PALTs for Different Sized Samples Based on the Results Presented in Table 1

\begin{tabular}{||c|c|c|c|c||}
\hline$n$ & $\tau^{*}$ & $n_{u}^{*}=n P_{u}$ & $n_{a}^{*}=n P_{a}$ & Optimal GAV \\
\hline 20 & 4.095819 & 11 & 4 & 0.00110 \\
\hline 25 & 4.033014 & 13 & 6 & 0.00049 \\
\hline 30 & 3.824391 & 16 & 7 & 0.00017 \\
\hline 40 & 3.652942 & 20 & 10 & 0.00013 \\
\hline 50 & 3.578992 & 26 & 12 & 0.00004 \\
\hline 75 & 3.345305 & 37 & 19 & 0.000002 \\
\hline 100 & 3.299687 & 49 & 26 & 0.000001 \\
\hline
\end{tabular}

T a b 1 e 6

The Results of Optimal Design of Step-Stress PALTs for Different Sized Samples Based on the Results Presented in Table 2

\begin{tabular}{||c|c|c|c|c||}
\hline$n$ & $\tau^{*}$ & $n_{u}^{*}=n P_{u}$ & $n_{a}^{*}=n P_{a}$ & Optimal GAV \\
\hline 20 & 3.566034 & 11 & 4 & 0.00112 \\
\hline 25 & 3.722411 & 13 & 6 & 0.00064 \\
\hline 30 & 3.601075 & 16 & 7 & 0.00046 \\
\hline 40 & 3.585876 & 20 & 13 & 0.00014 \\
\hline 50 & 3.371908 & 25 & 21 & 0.00010 \\
\hline 75 & 3.156042 & 35 & 29 & 0.00004 \\
\hline 100 & 3.133222 & 46 & & 0.00001 \\
\hline
\end{tabular}


Moreover, Tables 5-8 show the results of the optimal design of the life test. The optimal stress-change time $\tau^{*}$ is determined to minimize the GAV of the MLEs of the model parameters. Also, the expected optimal numbers of failed items under use and accelerated conditions are obtained for each sample size. Moreover, the optimal GAV of the MLEs of the model parameters are optimally determined for each sample size. As shown from the results, the optimal GAV decreases as the sample size increases.

$\mathrm{T}$ a b 1 e 7

The Results of Optimal Design of Step-Stress PALTs for Different Sized Samples Based on the Results Presented in Table 3

\begin{tabular}{|c|c|c|c|c|}
\hline$n$ & $\tau^{*}$ & $n_{u}^{*}=n P_{u}$ & $n_{a}^{*}=n P_{a}$ & Optimal GAV \\
\hline 20 & 3.98608 & 9 & 6 & 0.00037 \\
\hline 25 & 3.68533 & 11 & 8 & 0.00035 \\
\hline 30 & 3.56103 & 13 & 10 & 0.00023 \\
\hline 40 & 3.42640 & 17 & 13 & 0.00012 \\
\hline 50 & 3.55931 & 21 & 17 & 0.00005 \\
\hline 75 & 3.31212 & 30 & 26 & 0.00002 \\
\hline 100 & 3.21435 & 39 & 36 & 0.00001 \\
\hline
\end{tabular}

T a b 1 e 8

The Results of Optimal Design of Step-Stress PALTs for Different Sized Samples Based on the Results Presented in Table 4

\begin{tabular}{|c|c|c|c|c||}
\hline$n$ & $\tau^{*}$ & $n_{u}^{*}=n P_{u}$ & $n_{a}^{*}=n P_{a}$ & Optimal GAV \\
\hline 20 & 3.7044 & 6 & 9 & 0.002891 \\
\hline 25 & 3.8967 & 8 & 11 & 0.000125 \\
\hline 30 & 4.3621 & 10 & 13 & 0.000034 \\
\hline 40 & 3.9035 & 13 & 17 & 0.000012 \\
\hline 50 & 3.8494 & 15 & 22 & 0.000007 \\
\hline 75 & 3.3324 & 22 & 34 & 0.000006 \\
\hline 100 & 3.3432 & 29 & 46 & 0.000003 \\
\hline \hline
\end{tabular}

Conclusions. This paper considers the step-stress PALTs with failure-censored data from Burr type-XII distribution. Average values of the MLEs of the parameters and acceleration factor with MSEs and 95\% ACIs are obtained based on samples generated from Burr type-XII distribution of various combinations of true parameter values. Moreover, optimum test plans were developed such that the GAV of the MLEs of the model parameters is minimized. These plans determine the optimal value of the stress changepoint $\tau^{*}$ that minimizes the GAV. Accordingly, the quality of the statistical inference is improved. That is, more efficient MLEs of the model parameters are obtained.

Acknowledgments. This project was supported by the Agency for Post Graduate Studies \& Research, Faculty of Economics \& Political Science, Cairo University. 


\section{Appendix A.}

Derivation of the second-order partial derivatives:

$$
\begin{aligned}
& \frac{\partial^{2} \ln L}{\partial \beta^{2}}=-\frac{n_{a}}{\beta^{2}}-(c-1) \sum_{i=1}^{n} \delta_{2 i}\left(y_{i}-\tau\right) \frac{\left(y_{i}-\tau\right)}{\left(\tau+\beta\left(y_{i}-\tau\right)\right)^{2}}- \\
& -(k+1) c \sum_{i=1}^{n}\left(y_{i}-\tau\right) \delta_{2 i}\left[\left(y_{i}-\tau\right)(c-1) A^{c-2}\left(1+A^{c}\right)^{-1}-\right. \\
& \left.-\left(y_{i}-\tau\right) c A^{2(c-1)}\left(1+A^{c}\right)^{-2}\right]-k c\left(n-n_{0}\right)\left(y_{(r)}-\tau\right) \times \\
& \times\left[(c-1)\left(y_{(r)}-\tau\right) D^{c-2}\left(1+D^{c}\right)^{-1}-\left(y_{(r)}-\tau\right) c D^{2(c-1)}\left(1+D^{c}\right)^{-2}\right]= \\
& =-\frac{n_{a}}{\beta^{2}}-(c-1) \sum_{i=1}^{n} \delta_{2 i}\left(y_{i}-\tau\right)^{2} A^{-2}- \\
& -(k+1) c \sum_{i=1}^{n}\left(y_{i}-\tau\right)^{2} \delta_{2 i}\left[(c-1) A^{c-2}\left(1+A^{c}\right)^{-1}-c A^{2(c-1)}\left(1+A^{c}\right)^{-2}-\right. \\
& -k c\left(n-n_{0}\right)\left(y_{(r)}-\tau\right)^{2}\left[(c-1) D^{c-2}\left(1+D^{c}\right)^{-1}-c D^{2(c-1)}\left(1+D^{c}\right)^{-2}\right], \\
& \frac{\partial^{2} \ln L}{\partial \beta \partial c}=\sum_{i=1}^{n} \delta_{2 i}\left(y_{i}-\tau\right) A^{-1}-k\left(y_{(r)}-\tau\right)\left(n-n_{0}\right) \times \\
& \times\left[D^{c-1}\left(1+D^{c}\right)^{-1}+c\left(1+D^{c}\right)^{-1} D^{c-1} \ln D-c D^{c-1}\left(1+D^{c}\right)^{-2} D^{c} \ln D\right]- \\
& -(k+1) \sum_{i=1}^{n} \delta_{2 i}\left(y_{i}-\tau\right)\left[A^{c-1}\left(1+A^{c}\right)^{-1}+c\left(1+A^{c}\right)^{-1} A^{c-1} \ln A-\right. \\
& \left.-c A^{c-1}\left(1+A^{c}\right)^{-2} A^{c} \ln A\right] \\
& \frac{\partial^{2} \ln L}{\partial \beta \partial k}=-c \sum_{i=1}^{n} \delta_{2 i}\left(y_{i}-\tau\right) A^{c-1}\left(1+A^{c}\right)^{-1}-\left(y_{(r)}-\tau\right)\left(n-n_{0}\right) c D^{c-1}(1+D c)^{-1}, \\
& \frac{\partial^{2} \ln L}{\partial c^{2}}=-\frac{n_{0}}{c^{2}}-k\left(n-n_{0}\right) \ln D\left[\left(1+D^{c}\right)^{-1} D^{c} \ln D-\left(1+D^{c}\right)^{-2} D^{2 c} \ln D\right]- \\
& -(k+1)\left[\sum_{i=1}^{n} \delta_{1 i} \ln y_{i}\left\{\left(1+y_{i}^{c}\right)^{-1} y_{i}^{c} \ln y_{i}-y_{i}^{2 c}\left(1+y_{i}^{c}\right)^{-2} \ln y_{i}\right\}\right]- \\
& -(k+1)\left[\sum_{i=1}^{n} \delta_{2 i} \ln A\left\{\left(1+A^{c}\right)^{-1} A^{c} \ln A-A^{2 c}\left(1+A^{c}\right)^{-2} \ln A\right\}\right],
\end{aligned}
$$




$$
\begin{gathered}
\frac{\partial^{2} \ln L}{\partial c \partial k}=-\sum_{i=1}^{n} \delta_{1 i} \ln y_{i}\left\{\left(1+y_{i}^{c}\right)^{-1} y_{i}^{c} \ln y_{i}\right\}-\sum_{i=1}^{n} \delta_{2 i} \ln A\left(1+A^{c}\right)^{-1} A^{c} \ln A- \\
-\left(n-n_{0}\right)\left(1+D^{c}\right)^{-1} D^{c} \ln D,
\end{gathered}
$$

and

$$
\frac{\partial^{2} \ln L}{\partial k^{2}}=-\frac{n_{0}}{k^{2}} .
$$

\section{Appendix B.}

The determinant of $F$ and its partial derivative w.r.t. $\tau$. The determinant of $F$ is given by

$$
|F|=f_{11}\left(f_{22} f_{33}-f_{23}^{2}\right)-f_{12}\left(f_{12} f_{33}-f_{13} f_{23}\right)+f_{13}\left(f_{12} f_{23}-f_{13} f_{22}\right) .
$$

Its partial derivative w.r.t. $\tau$ is obtained as

$$
\begin{gathered}
\frac{\partial|F|}{\partial \tau}=f_{11}\left(f_{22}^{\prime} f_{33}+f_{22} f_{33}^{\prime}-2 f_{23} f_{23}^{\prime}\right)+f_{11}^{\prime}\left(f_{22} f_{33}-f_{23}^{2}\right)- \\
-f_{12}\left(f_{12}^{\prime} f_{33}+f_{12} f_{33}^{\prime}-f_{13}^{\prime} f_{23}-f_{13} f_{23}^{\prime}\right)-f_{12}^{\prime}\left(f_{12} f_{33}-f_{13} f_{23}\right)+ \\
+f_{13}\left(f_{12}^{\prime} f_{23}+f_{12} f_{23}^{\prime}-f_{13}^{\prime} f_{22}-f_{13} f_{22}^{\prime}\right)+f_{13}^{\prime}\left(f_{12} f_{23}-f_{13} f_{22}\right) .
\end{gathered}
$$

where

$$
\begin{gathered}
f_{11}^{\prime}=(c-1) \sum_{i=1}^{n} \delta_{2 i}\left[-2\left(y_{i}-\tau\right) A^{-2}-2\left(y_{i}-\tau\right)^{2} A^{-3}(1-\beta)\right]+ \\
+(k+1) c \sum_{i=1}^{n}(c-1) \delta_{2 i}\left[-2\left(y_{i}-\tau\right) A^{c-2}\left(1+A^{c}\right)^{-1}+\left(y_{i}-\tau\right)^{2} \times\right. \\
\left.\times(1-\beta)\left((c-2) A^{c-3}\left(1+A^{c}\right)^{-1}-c A^{2 c-3}\left(1+A^{c}\right)^{-2}\right)\right]- \\
-(k+1) c \sum_{i=1}^{n} c \delta_{2 i}\left[-2\left(y_{i}-\tau\right) A^{2(c-1)}\left(1+A^{c}\right)^{-2}+\left(y_{i}-\tau\right)^{2} \times\right. \\
\left.\times 2(1-\beta)\left((c-1) A^{2 c-3}\left(1+A^{c}\right)^{-2}-c A^{3(c-1)}\left(1+A^{c}\right)^{-3}\right)\right]+ \\
+k c\left(n-n_{0}\right)(c-1)\left[-2\left(y_{(r)}-\tau\right) D^{c-2}\left(1+D^{c}\right)^{-1}+(1-\beta)\left(Y_{c}-\tau\right)^{2} \times\right. \\
\left.\times\left((c-2) D^{c-3}\left(1+D^{c}\right)^{-1}-c D^{2 c-3}\left(1+D^{c}\right)^{-2}\right)\right]- \\
-k c^{2}\left(n-n_{0}\right)\left[-2\left(y_{(r)}-\tau\right) D^{2(c-1)}\left(1+D^{c}\right)^{-2}+2\left(y_{(r)}-\tau\right)^{2}(1-\beta) \times\right. \\
\left.\times\left((c-1) D^{2 c-3}\left(1+D^{c}\right)^{-2}-D^{3(c-1)} c\left(1+D^{c}\right)^{-3}\right)\right], \\
f_{22}^{\prime}=k\left(n-n_{0}\right)(1-\beta)\left[2 D^{c-1}\left(1+D^{c}\right)^{-1} \ln D^{-} c(\ln D)^{2} \times\right. \\
\left.\times\left(D^{2 c-1}\left(1+D^{c}\right)^{-2}+D^{c-1}\left(1+D^{c}\right)^{-1}\right)\right]-
\end{gathered}
$$




$$
\begin{aligned}
& -k\left(n-n_{0}\right)(1-\beta)\left[D^{2 c-1}\left(1+D^{c}\right)^{-2} 2 \ln D+2 c(1-\beta)(\ln D)^{2} \times\right. \\
& \left.\times\left\{-D^{3 c-1}\left(1+D^{c}\right)^{-3}+D^{2 c-1}\left(1+D^{c}\right)^{-2}\right\}\right]+ \\
& +(k+1)(1-\beta) \sum_{i=1}^{n} \delta_{2 i}\left[2 A^{c-1}\left(1+A^{c}\right)^{-1} \ln A+c(\ln A)^{2} \times\right. \\
& \left.\times\left\{-\left(1+A^{c}\right)^{-2} A^{2 c-1}+\left(1+A^{c}\right)^{-1} A^{c-1}\right\}\right]- \\
& -(k+1)(1-\beta) \sum_{i=1}^{n} \delta_{2 i}\left[2 A^{2 c-1}\left(1+A^{c}\right)^{-2} \ln A+2 c(\ln A)^{2} \times\right. \\
& \times\left\{\left(1+A^{c}\right)^{-2} A^{2 c-1}-\left(1+A^{c}\right)^{-3} A^{3 c-1}\right\}, \\
& f_{33}^{\prime}=0 \text {, } \\
& f_{23}^{\prime}=\sum_{i=1}^{n} \delta_{2 i}(1-\beta)\left[2 A^{c-1}\left(1+A^{c}\right)^{-1} \ln A+c(\ln A)^{2} \times\right. \\
& \left.\times\left(1+A^{c}\right)^{-1} A^{c-1}-\left(1+A^{c}\right)^{-1} A^{2 c-1}\right]+ \\
& +\left(n-n_{0}\right)(1-\beta)\left[-D^{2 c-1}\left(1+D^{c}\right)^{-2} c \ln D+\left(1+D^{c}\right)^{-1} D^{c-1}\{c \ln D+1\}\right], \\
& f_{12}^{\prime}=\sum_{i=1}^{n} \delta_{2 i}\left[A^{-1}+(1-\beta)\left(y_{i}-\tau\right) A^{-2}\right]+k\left(n-n_{0}\right)\left\{(1-\beta)\left(Y_{c}-\tau\right) \times\right. \\
& \times\left[D^{c-2}(c-1)\left(1+D^{c}\right)^{-1}-c\left(1+D^{c}\right)^{-2} D^{2(c-1)}\right]-D^{c-1}\left(1+D^{c}\right)^{-1}- \\
& -c\left(1+D^{c}\right)^{-1} D^{c-1} \ln D+c\left(Y_{c}-\tau\right)(1-\beta)\left\{-D^{2(c-1)} c\left(1+D^{c}\right)^{-2} \ln D+\right. \\
& \left.+D^{c-2}\left(1+D^{c}\right)^{-1}[1+(c-1) \ln D]\right\}+c D^{2 c-1}\left(1+D^{c}\right)^{-2} \ln D-c(1-\beta)\left(Y_{c}-\tau\right) \times \\
& \left.\times\left[D^{2 c-2}\left(1+D^{c}\right)^{-2}-2 c\left(1+D^{c}\right)^{-3} D^{3 c-2} \ln D+(2 c-1)\left(1+D^{c}\right)^{-2} D^{2 c-2} \ln D\right]\right\}+ \\
& +(k+1) \sum_{i=1}^{n} \delta_{2 i}\left(y_{i}-\tau\right)\{(1-\beta) \times
\end{aligned}
$$$$
\times\left[(c-1) A^{c-2}\left(1+A^{c}\right)^{-1}-c A^{2(c-1)}\left(1+A^{c}\right)^{-2}-c^{2} A^{2(c-1)}\left(1+A^{c}\right)^{-2} \ln A+\right.
$$$$
+c A^{c-2}\left(1+A^{c}\right)^{-1}(1+(c-1) \ln A)-c A^{2(c-1)}\left(1+A^{c}\right)^{-2}+
$$$$
\left.+2 c^{2} A^{3 c-2}\left(1+A^{c}\right)^{-3} \ln A-c(2 c-1) A^{2 c-2}\left(1+A^{c}\right)^{-2} \ln A\right\}-
$$$$
-\left[A^{c-1}\left(1+A^{c}\right)^{-1}+c\left(1+A^{c}\right)^{-1} A^{c-1} \ln A-c A^{2 c-1}\left(1+A^{c}\right)^{-2} \ln A\right],
$$ 


$$
\begin{gathered}
f_{13}^{\prime}=\sum_{i=1}^{n} \delta_{2 i} c\left\{\left(y_{i}-\tau\right)(1-\beta)\left[(c-1) A^{c-2}\left(1+A^{c}\right)^{-1}-c A^{2(c-1)}\left(1+A^{c}\right)^{-2}\right]-\right. \\
\left.-A^{c-1}\left(1+A^{c}\right)^{-1}\right\}+\left(n-n_{0}\right) c\left[( y _ { ( r ) } - \tau ) ( 1 - \beta ) \left[(c-1) D^{c-2}\left(1+D^{c}\right)^{-1}-\right.\right. \\
\left.\left.-c D^{2(c-1)}\left(1+D^{c}\right)^{-2}\right]-D^{c-1}\left(1+D^{c}\right)^{-1}\right] .
\end{gathered}
$$

\section{Резиме}

Проведено оптимальне планування частково прискорених ресурсних досліджень при покроковій зміні напружень із використанням цензурованих у часі даних із розподілу Бурра XII типу. У рамках концепції максимальної імовірності оцінено коефіцієнт прискорення досліджень і параметри розподілу. Як критерій оптимізації частково прискорених ресурсних досліджень, що плануються, використано мінімізацію узагальненої асимптотичної дисперсії для показників максимальної імовірності параметрів розподілу. Ефективність запропонованого методу показано на прикладі чисельних розрахунків.

1. W. Nelson, Accelerated Testing: Statistical Models, Test Plans, and Data Analysis, John Wiley \& Sons, New York (1990).

2. Ali A. Ismail and A. Al Tamimi, "Optimum constant-stress partially accelerated life test plans using type-I censored data from the inverse Weibull distribution," Strength Mater., 49, No. 6, 847-855 (2017).

3. P. K. Goel, Some Estimation Problems in the Study of Tampered Random Variables, Technical Report No. 50, Department of Statistics, Carnegie Mellon University, Pittsburgh, PA (1971).

4. D. S. Bai and S. W. Chung, "Optimal design of partially accelerated life tests for the exponential distribution under type-I censoring," IEEE Trans. Reliab., 41, 400-406 (1992).

5. Ali A. Ismail, "Statistical inference for a step-stress partially accelerated life test model with an adaptive Type-I progressively hybrid censored data from Weibull distribution," Stat. Pap., 57, No. 2, 271-301 (2016).

6. Ali A. Ismail, "Optimum failure-censored step-stress life test plans for the Lomax distribution," Strength Mater., 48, No. 3, 437-443 (2016).

7. Ali A. Ismail, "Planning step-stress life tests for the generalized Rayleigh distribution under progressive type-II censoring with binomial removals," Strength Mater., 49, No. 2, 292-306 (2017).

8. Ali A. Ismail and K. Al-Habardi, "On designing time-censored step-stress life test for the Burr type-XII distribution," Strength Mater., 49, No. 5, 699-709 (2017).

9. I. W. Burr, "Cumulative frequency distribution," Ann. Math. Stat., 13, No. 2, 215-232 (1942).

10. D. S. Bai, S. W. Chung, and Y. R. Chun, "Optimal design of partially accelerated life tests for the lognormal distribution under Type-I censoring," Reliab. Eng. Syst. Safe., 40, No. 1, 85-92 (1993). 